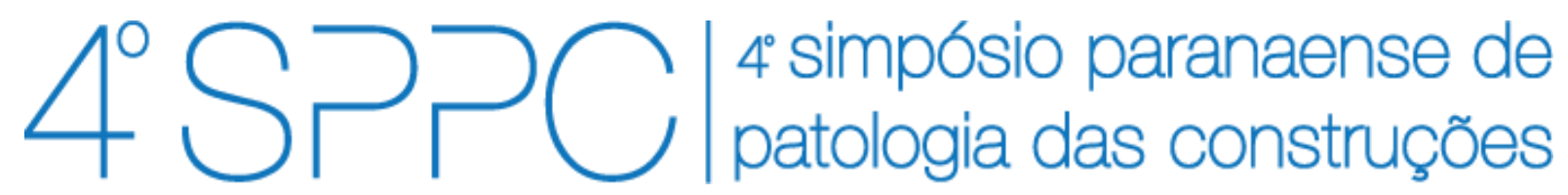

ISSN 2526-7248 artigo n. 4SPPC126, pp. 243-252, 2019

\title{
Concreto com substituição de sílica de casca de arroz e sílica ativa: efeitos do ataque por sulfato de magnésio
}

\author{
Medeiros, João Marcos ${ }^{1}$; Andrade, Fabricio Cunha², de Capraro, Ana Paula ${ }^{3}$, \\ Medeiros, Marcelo Henrique Farias ${ }^{4}$ \\ 1 Especialista, UFPR, PPGECC, e-mail: engcivilmedeiros@yahoo.com \\ 2 Especialista, UFPR, PPGECC, e-mail: fabriciocandrade@yahoo.com \\ 3 Doutoranda, UFPR, PPGECC, e-mail: anapcapraro@gmail.com \\ ${ }^{4}$ Doutor, UFPR, PPGECC e-mail: medeiros.ufpr@gmail.com
}

\begin{abstract}
Resumo: Entre os mecanismos de degradação do concreto, o ataque por sulfatos é um dos menos estudados e no caso do sulfato de magnésio, existem ainda menos estudos e domínio do conhecimento, pesquisas apontam que a substituição de pozolânicas pode ser um caminho útil para tornar os concretos mais duráveis em certas condições de exposição. O presente estudo visou avaliar o uso de cimento CP V ARI de forma combinada com substituição de sílica ativa e sílica de casca de arroz, em concreto convencional, exposto ao ataque do sulfato de magnésio, com uma concentração de $7 \%$ de $\mathrm{MgSO}_{4}$ em solução aquosa, resultando em 67,63 g/L de $\mathrm{MgSO}_{4}$, ao longo de 180 dias. Os resultados obtidos indicam que o tempo de exposição foi pouco para observar expansão e perda de resistência, porém, a técnica de MEV foi útil para evidenciar a formação de cristais aciculares de etringita nos poros de todos os concretos. Isso mostra que no período de teste as séries de ensaio estavam na fase inicial de ataque por sulfatos. em que a rede de poros são preenchidas com etringita.
\end{abstract}

Palavras-chave: Concreto, adições pozolânicas, ataque por sulfato de magnésio, etringita.

Abstract: Considering the concrete degradation mechanisms, sulfate attack is one of the least studied and. in case of magnesium sulphate, there are even fewer studies and mastery of knowledge, research indicates that the substitution of Pozolanic additions can be a useful way to make concretes more durable under certain exposure conditions. The present study aimed to evaluate the use of CP V ARI cement, combined with additions of active silica and rice husk silica in conventional concrete, exposed to the attack of magnesium sulphate with a concentration of $7 \%$ of $\mathrm{MgSO}_{4}$ in aqueous solution using, $67.63 \mathrm{~g} / \mathrm{L}$ of $\mathrm{MgSO}_{4}$, over 180 days. The results indicate that the exposure was not enough to observe expansion and loss of strength. However, the scan electronic microscopy (SEM) technique was useful to evidence the formation of acicular crystals of ettringite in the pores of all exposed concretes. This shows that in the test period the series were in the initial phase of attack by sulphates in which the pores go to fill with ettringite.

Keywords: Concrete, pozzolanic additions, attack by magnesium sulphate, ettringite. 
MEDEIROS, J.M.; ANDRADE, F. C.; CAPRARO, A. P.; MEDEIROS, M. H. F. CONCRETO COM SUBSTITUIÇÃO DE SÍLICA DE CASCA DE ARROZ E SÍLICA ATIVA: EFEITOS DO ATAQUE POR SULFATO DE MAGNÉSIO. $4^{\circ}$ Simpósio Paranaense de Patologia das Construções (40 SPPC), artigo 4SPPC126, pp. 243 - 252, 2019. DOI: 10.4322/2526-7248.046

\section{Introdução}

Os mecanismos de degradação resultantes das reações químicas dos sulfatos em estruturas de concreto de cimento Portland têm um grande impacto econômico, principalmente em função do tipo de construção, como é o caso de dutos de águas de despejo industrial, redes de esgoto doméstico, obras em solos com águas subterrâneas, barragens de rejeitos. A exposição do concreto a soluções com presença de sulfato possibilita a ocorrência de reações químicas com formação de subprodutos, como a etringita, taumasita e gipsita, que podem provocar expansões internas, causando fissuras e perda significativa de resistência mecânica [1].

A degradação do concreto pode causar a solubilização dos íons cálcio dos compostos hidratados, como da alita e belita, por reação substitutiva. A deterioração do concreto, devido ao ataque por sulfato, é considerada um problema complexo e depende de muitos fatores, dentre eles: o tipo de cimento, a relação água/ cimento, a estrutura de poros dos hidratos formados, a utilização de adições minerais (como cinzas volantes, escória de alto forno, sílica ativa, sílica de casca de arroz), o tipo do sulfato, a sua concentração e a presença de mais de um tipo de agressividade de íons, além das condições ambientais, como a temperatura e ciclos de secagem-umedecimento [2].

O ataque por sulfato externo ao concreto ocorre quando o contaminante se encontra no ambiente, como na água ou solo próximo a estrutura, possibilitando a penetração do agente agressivo nos poros da matriz do concreto. Por outro lado, o ataque de sulfato de origem interna, ocorre quando a fonte de sulfato está dentro do concreto, podendo ser do cimento com alto teor de sulfato ou agregado contaminado [3]. Os danos causados pelo ataque externo são mais frequentes, pois os solos com sulfato de sódio, potássio, magnésio e cálcio são as principais fontes dos íons sulfato, o que por fim acaba sendo disseminado na água subterrânea.

Devido à decomposição dos silicatos de cálcio hidratados $(\mathrm{C}-\mathrm{S}-\mathrm{H})$ e do $\mathrm{Ca}(\mathrm{OH})_{2}(\mathrm{CH}$, hidróxido de cálcio), o sulfato de magnésio tem um efeito mais danoso que outros sulfatos [4]. O trabalho de Souza, Medeiros e Hope Filho [5] compara a agressividade do sulfato de sódio com o sulfato de magnésio e comprova a maior agressividade do segundo. Além disso, o trabalho citado evidenciou que o cimento RS (resistente a sulfatos, que só estabelece a exposição ao sulfato de sódio como método de teste) não tem capacidade mais resistente ao sulfato de magnésio, se comparado ao cimento não classificado como RS.

A principal característica do ataque por sulfato de magnésio é o consumo do silicato de cálcio hidratado $\left(3 \mathrm{CaO} .2 \mathrm{SiO}_{2} .3 \mathrm{H}_{2} \mathrm{O}=\mathrm{C}-\mathrm{S}-\mathrm{H}\right)$, resultando na substituição do cálcio pelo magnésio, formando o silicato de magnésio hidratado e consecutivamente ocorre a perda das propriedades cimentantes. Além disto, também há o surgimento de gipsita $\left(\mathrm{CaSO}_{4} .2 \mathrm{H}_{2} \mathrm{O}\right)$, na solução dos poros da matriz hidratada, através das reações com o hidróxido de cálcio [5].

A conversão de hidróxido de cálcio em gipsita é acompanhada pela formação de hidróxido de magnésio, que é pouco solúvel e reduz a alcalinidade do sistema. Assim, a estabilidade do C-S-H é reduzida, e ele também é atacado pela solução de sulfato, tornando o ataque mais severo [6]. 
O uso de adições minerais na composição do material ligante, em substituição parcial ao cimento, provoca alterações microestruturais que interferem na porosidade da matriz hidratada, na distribuição do tamanho dos poros e na interconectividade dos mesmos, o que dificulta as trocas de umidade, íons e gases com o meio e a redução das fissuras de origem térmica em função da redução do calor de hidratação [7].

De acordo com Mehta e Monteiro [6], a sílica ativa promove um refinamento da dimensão dos poros e diminuição da dimensão dos cristais de $\mathrm{CH}$ ao redor das partículas de pozolana e uma densificação da pasta e da interface, melhorando as propriedades do concreto, especialmente as relacionadas com a penetração de líquidos e gases.

Este estudo teve o objetivo de investigar a influência da substituição parcial do cimento Portland (CP V - ARI) por sílica de casca de arroz (SCA) e sílica ativa (SA) no ataque externo por sulfato de magnésio, analisando as propriedades de corpos de provas de concreto submetidos ao ataque externo de sulfato.

\section{Materiais e métodos}

Para a produção dos concretos do estudo foi utilizado o cimento Portland de alta resistência inicial $\mathrm{CP} V$ - ARI pois, dentro das opções disponíveis no mercado, é o que contém a menor porcentagem de adições, sendo considerado o mais puro, com massa específica de $3,09 \mathrm{~g} / \mathrm{cm}^{3}$. Como agregado miúdo foi adotada uma areia natural de rio, com massa específica de $2,16 \mathrm{~g} / \mathrm{cm}^{3}$ e como agregado graúdo uma rocha de origem basáltica, com massa específica de $2,80 \mathrm{~g} / \mathrm{cm}^{3}$.

As substituições utilizadas foram a sílica de casca de arroz e uma sílica ativa, escolhidas por serem materiais de alta reatividade pozolânica, assim como relatado no trabalho de Medeiros et al. [8]. O uso destas adições foi realizado pela possibilidade de melhoramento da matriz do composto, ou seja, pelo possível refinamento dos poros e consequente diminuição da porosidade, e também por reduzir os produtos hidratados disponíveis para as reações deletérias [9].

A Tabela 1 mostra os dados de massa específica e área específica BET dos aglomerantes estudados.

Tabela 1: Características físicas das adições minerais

\begin{tabular}{lcc}
\hline \multirow{2}{*}{ Adição Mineral } & \multicolumn{2}{c}{ Características físicas } \\
& BET $\left(\mathrm{m}^{2} / \mathrm{g}\right)$ & Massa esp. $\left(\mathrm{g} / \mathrm{cm}^{3}\right)$ \\
\hline Cimento CPV ARI & 1,070 & 3,13 \\
Sílica Ativa & 20,238 & 2,18 \\
Sílica Casca Arroz & 14,692 & 2,12 \\
\hline
\end{tabular}

Para o desenvolvimento do traço referência (REF) foi adotado o $f_{c k}$ de $35 \mathrm{MPa}$ de resistência à compressão, além de outros dois traços com a substituição de $10 \%$ da massa do cimento pela sílica de casca de arroz (SCA) e sílica ativa (SA), conforme apresentado na Tabela 2. 

das Construções (40 SPPC), artigo 4SPPC126, pp. 243 - 252, 2019. DOI: 10.4322/2526-7248.046

Tabela 2: Proporção de mistura dos concretos

\begin{tabular}{cccccc}
\hline Traço & Cimento & Água & $\begin{array}{c}\text { Agregado. } \\
\text { Miúdo }\end{array}$ & $\begin{array}{c}\text { Agregado. } \\
\text { Graúdo }\end{array}$ & Sílica \\
\hline \multirow{2}{*}{ - REF } & $1,00 \mathrm{~kg}$ & $0,45 \mathrm{~kg}$ & $1,90 \mathrm{~kg}$ & $2,47 \mathrm{~kg}$ & $0,00 \mathrm{~kg}$ \\
& $0,32 \mathrm{~cm}^{3}$ & $0,45 \mathrm{~cm}^{3}$ & $0,88 \mathrm{~cm}^{3}$ & $0,88 \mathrm{~cm}^{3}$ & $0,00 \mathrm{~cm}^{3}$ \\
\hline \multirow{2}{*}{ II - SCA } & $0,90 \mathrm{~kg}$ & $0,45 \mathrm{~kg}$ & $1,90 \mathrm{~kg}$ & $2,47 \mathrm{~kg}$ & $0,10 \mathrm{~kg}$ \\
& $0,29 \mathrm{~cm}^{3}$ & $0,45 \mathrm{~cm}^{3}$ & $0,88 \mathrm{~cm}^{3}$ & $0,88 \mathrm{~cm}^{3}$ & $0,05 \mathrm{~cm}^{3}$ \\
\hline \multirow{2}{*}{ III-SA } & $0,90 \mathrm{~kg}$ & $0,45 \mathrm{~kg}$ & $1,90 \mathrm{~kg}$ & $2,47 \mathrm{~kg}$ & $0,10 \mathrm{~kg}$ \\
& $0,29 \mathrm{~cm}^{3}$ & $0,45 \mathrm{~cm}^{3}$ & $0,88 \mathrm{~cm}^{3}$ & $0,88 \mathrm{~cm}^{3}$ & $0,05 \mathrm{~cm}^{3}$ \\
\hline
\end{tabular}

No período de 08 a 12 de agosto de 2018 foram moldados e desmoldados 90 corpos de prova divididos em: 18 prismáticos de $75 \times 75 \times 285 \mathrm{~mm}$ e 72 prismáticos de $40 \times$ $40 \times 160 \mathrm{~mm}$, conforme a Tabela 3.

Tabela 3: Total de corpos de prova

\begin{tabular}{lcc}
\hline Série & $\begin{array}{c}\text { Prismático } \\
\mathbf{7 5 \times 7 5 \times 2 8 5 m m}\end{array}$ & $\begin{array}{c}\text { Prismático } \\
\mathbf{4 0 \times 4 0 \times 1 6 0 m m}\end{array}$ \\
\hline I - REF & 6 & 24 \\
II - SCA & 6 & 24 \\
III - SA & 6 & 24 \\
\hline Total & $\mathbf{1 8}$ & $\mathbf{7 2}$ \\
\hline
\end{tabular}

Os corpos de prova permaneceram um período de 14 dias de cura em câmara úmida (UR $\geq 95 \pm 2 \%$ e $T=21 \pm 2 \stackrel{\circ}{\circ}$ ). Sendo divididos em dois grupos: o primeiro imerso em uma solução de água saturada com hidróxido de cálcio, com uma concentração de $50 \%$, utilizando $500,0 \mathrm{~g} / \mathrm{L}$ de $\mathrm{Ca}(\mathrm{OH})_{2}$. O segundo foi exposto por imersão a uma solução agressiva, de sulfato de magnésio $\left(\mathrm{MgSO}_{4}\right)$, sendo empregada uma concentração de $7 \%$, utilizando $67,63 \mathrm{~g} / \mathrm{L}$ de $\mathrm{MgSO}_{4}$ e a relação volume de solução/ volume de amostras foi fixada em 4,0/1,0, sendo que, as variáveis ambientais (temperatura, umidade relativa, pressão atmosférica, etc.) não foram controladas, mas foram garantidas as mesmas condições para os dois grupos de corpos de prova por um período de 180 dias.

Com o objetivo de analisar o comportamento dos concretos expostos à solução agressiva de sulfato de magnésio foram realizados os ensaios de variação dimensional, resistência à compressão axial e à tração na flexão e microscopia eletrônica de varredura (MEV).

A análise da variação dimensional foi realizada periodicamente ao longo dos 180 dias de exposição dos corpos de prova, por meio de um pórtico metálico acoplado a um relógio comparador. As amostras $75 \times 75 \times 285 \mathrm{~mm}$ foram posicionadas no pórtico metálico, sempre com a mesma face voltada para cima, e a leitura válida foi considerada como a menor identificada pelo aparelho após giro de $360^{\circ}$ da barra. A expansão ou retração individual das barras é dada pela diferença entre o valor medido no tempo de exposição ao $\mathrm{MgSO}_{4}$ e a leitura inicial a 15 dias de exposição. 

das Construções (40 SPPC), artigo 4SPPC126, pp. 243 - 252, 2019. DOI: 10.4322/2526-7248.046

Os ensaios de resistência à compressão e à resistência a tração na flexão foram realizados em três idades distintas, sendo elas: 65, 96 e 180 dias, nos corpos de prova $40 \times 40 \times 160 \mathrm{~mm}$.

O ensaio de MEV (Microscopia Eletrônica de varredura) foi realizado em um microscópio FEG SEM, Tescan, Mira 3, com fragmentos das amostras rompidas nos ensaios de resistência mecânica. O objetivo do ensaio foi a identificação de produtos deletérios que pudessem comprovar a ocorrência do ataque de sulfatos no período estudado. Fragmentos foram recolhidos na última idade analisada, 180 dias, e 0 ensaio foi realizado na sequência sobre a superfície de fratura das amostras. Em um primeiro momento as amostras foram coladas ao porta amostras com esmalte de grafite, para torná-las condutoras e possibilitar a identificação de elementos presentes por meio da técnica de EDS (Espectroscopia de energia dispersiva). Na sequência as amostras foram metalizadas a ouro e as imagens obtidas.

\section{Resultados}

\subsection{Variação Dimensional}

A variação dimensional observada para as três séries estudadas na solução agressiva de sulfato de magnésio aponta a retração ao longo do período estudado, identificando uma variação na ordem de 0,08 mm, conforme a Figura 1.

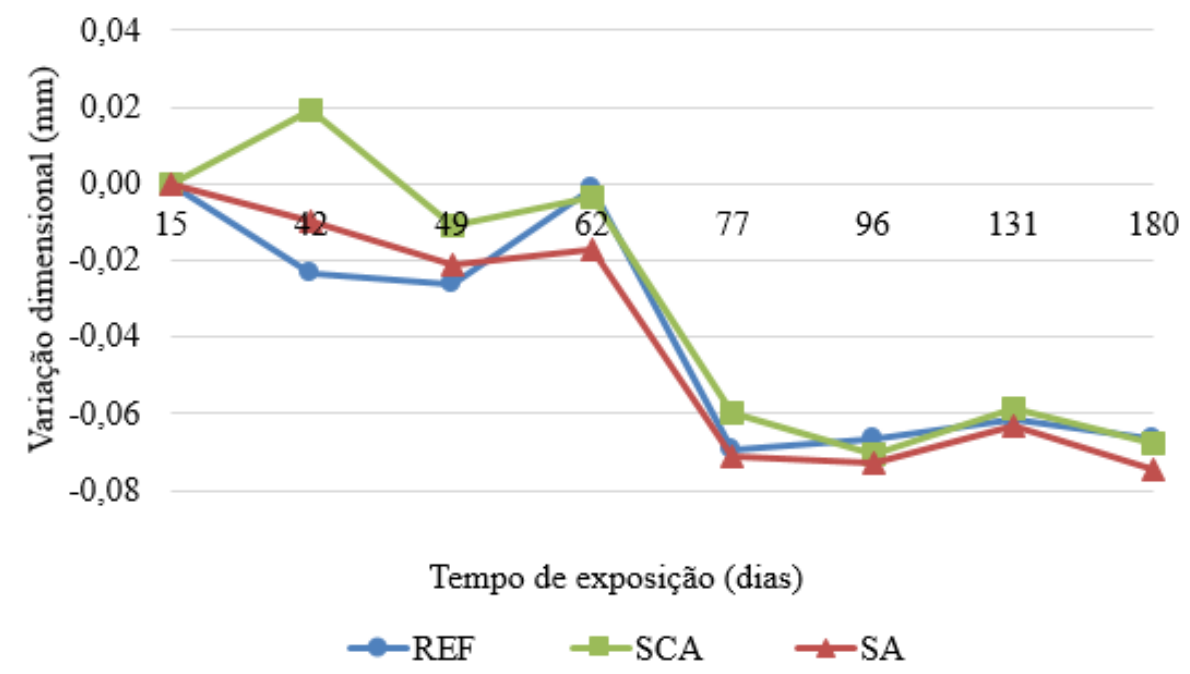

Figura 1: Ensaio de variação dimensional - Solução de $\mathrm{MgSO}_{4}$.

Com o resultado obtido não é possível indicar melhorias na matriz cimentícia pelo uso das adições, pois as três se comportaram de forma semelhante até a idade estudada, os resultados estão de acordo com o observado por Souza, Medeiros e Hope Filho [8].

Uma explicação para este comportamento é que o compósito cimentício tem tendência a apresentar retração química nas primeiras idades e o processo de degradação com ataque por sulfato de magnésio tem o efeito contrário, pois forma 

das Construções (40 SPPC), artigo 4SPPC126, pp. 243 - 252, 2019. DOI: 10.4322/2526-7248.046

compostos expansivos como gipsita e etringita, contudo, o efeito é nulo pois provavelmente os produtos expansivos gerados ainda não foram suficientes para preencher os poros do concreto.

Desse modo, a análise comparativa entre os resultados médios, quando aplicado o teste de Tukey, para 180 dias, indicam equivalência estatística entre todas as séries, sendo assim, a utilização ou não das adições minerais (sílica ativa e cinza de casca de arroz) não alterou o comportamento dos concretos para as condições e tempo de exposição estudadas.

\subsection{Resistências à compressão axial}

Os resultados da resistência à compressão axial para as três séries estudadas na solução de sulfato de magnésio apresentaram um comportamento semelhante, contudo, o teste estatístico aplicado pode diferenciar a série SA, com as outras duas, na idade de 65 dias, sendo ela a responsável pela maior resistência, conforme Figura 02.

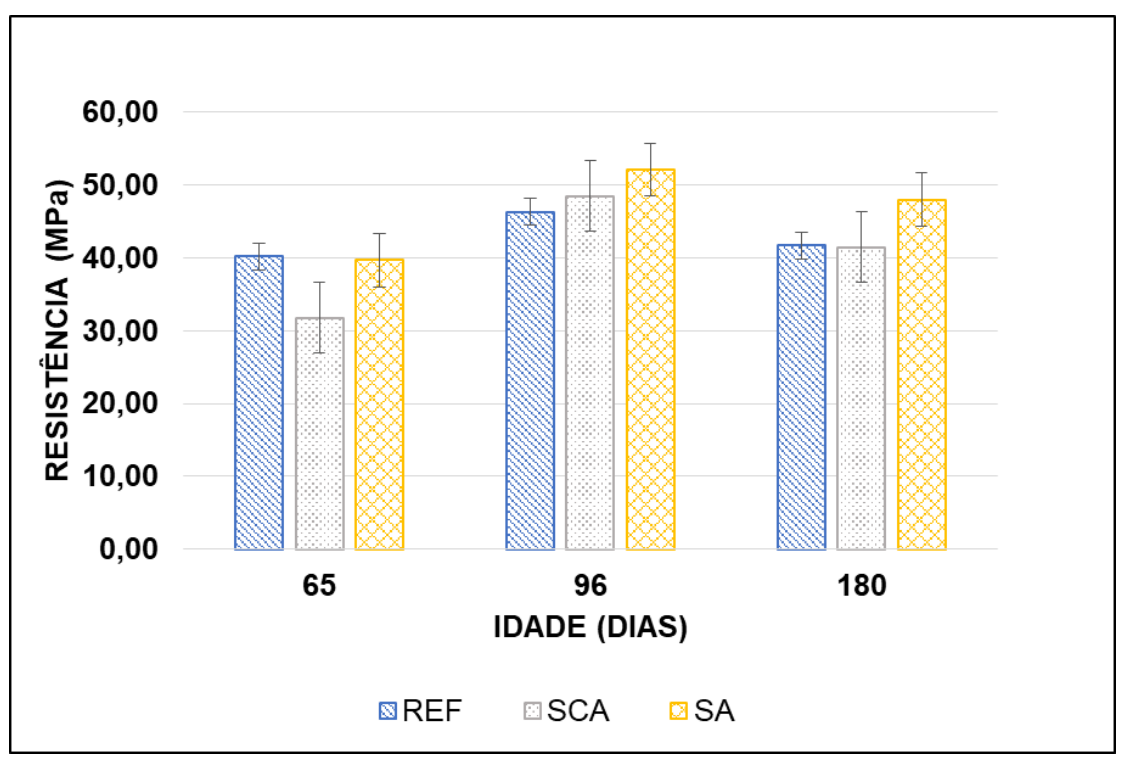

Figura 2: Resistência à Compressão - Solução de $\mathrm{MgSO}_{4}$.

Observa-se que na idade de 65 o concreto o traço SCA apresentou um resultado de $31,75 \mathrm{MPa}$, enquanto o REF e SA o resultado foi de $40 \mathrm{MPa}$, portanto $20 \%$, deste modo, pode-se inferir a sílica de casca de arroz apresentou reatividade e não contribui para o aumento da resistência a compressão.

Aos 96 dias todas as séries tiveram um aumento nos valores de resistência a compressão, com destaque para a série com SA que ultrapassou os $50 \mathrm{Mpa}$, de modo geral, as séries tiverem valores acima dos $45 \mathrm{Mpa}$. Nesta idade, a série referência e a série com sílica ativa foram consideradas estatisticamente equivalentes, com destaque o concreto com adição de sílica devido a um maior refinamento da estrutura de poros e ao efeito pozolânico, superior a 18 \% a REF.

Aos 180 dias, a série REF e a SCA apresentaram uma resistência de $41 \mathrm{MPa}, 26 \%$ inferior a média dos 96 dias, indicando que a influência do ataque externo de sulfato 
de magnésio. Segundo Marchand \& Skalny [10], quando expostas ao $\mathrm{MgSO}_{4}$, as argamassas podem ter uma elevada redução de resistência à compressão, com perda de 17,9 \%, quando comparada com o resultado de resistência à compressão para exposição ao hidróxido de cálcio. A redução da propriedade está associada à decomposição dos cristais de C-S-H, e, consequentemente, a composição de estruturas $\mathrm{M}-\mathrm{S}-\mathrm{H}$, que possuem pouca, ou nenhuma característica aglomerante e de resistência.

Deste modo, para este experimento não foi possível comprovar tal fenômeno, uma hipótese para tal pode ser com relação ao material estudado, pela composição da argamassa ser só de finos as alterações na matriz podem ocorrer de modo mais acelerado do que em misturas de concreto, uma vez que o trabalho de Marchand \& Skalny [10] foi realizado em argamassa e o presente estudo foi conduzido em concreto.

\subsection{Resistência à tração na flexão}

Os resultados médios de resistência à tração na flexão para as três séries estudadas na solução de sulfato de magnésio, apresentaram um comportamento semelhante, de acordo com o teste de Tukey com 95 \% de confiança, nas três idades analisadas, conforme a Figura 03.

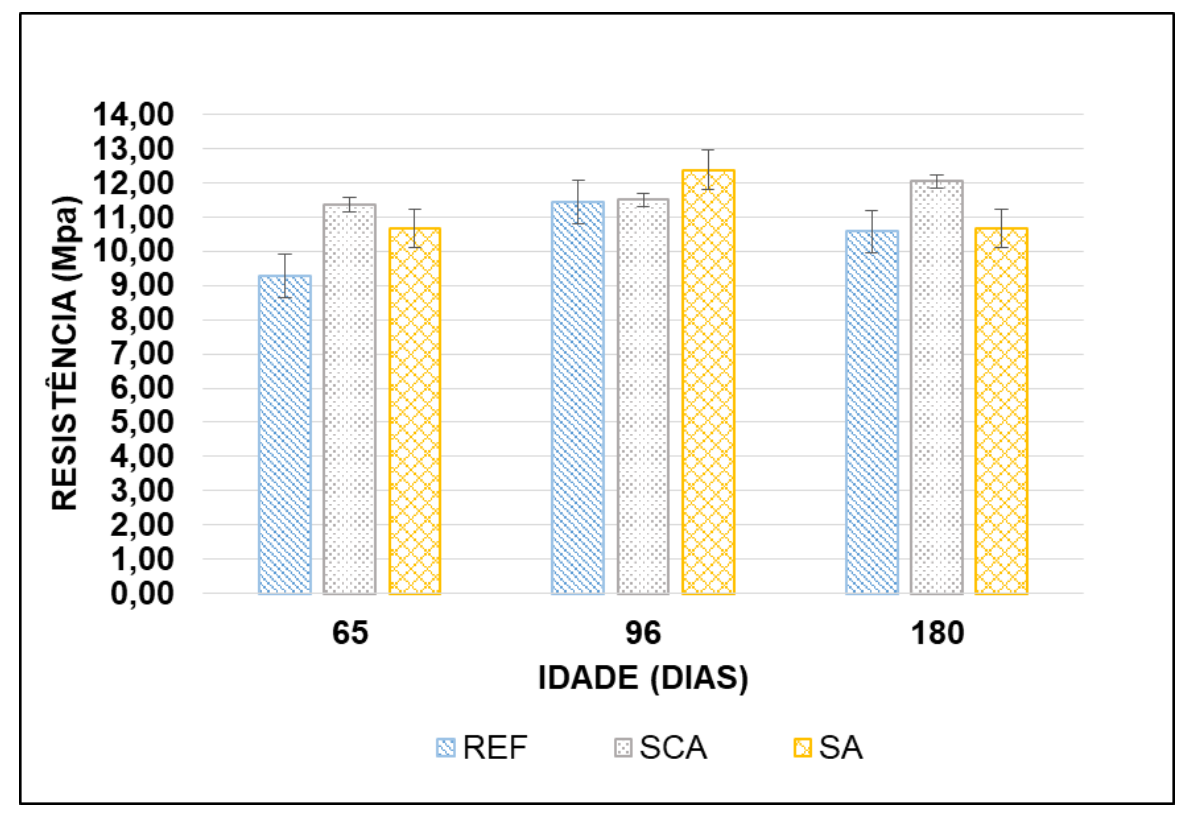

Figura 3: Resistência à tração na flexão - Solução de $\mathrm{MgSO}_{4}$.

Verifica-se que a série SCA apresenta valor de resistência à tração na flexão $15 \%$ superior comparado como o traço REF aos 65 dias. Aos 96 dias a série SA apresentou um valor de $8 \%$ superior a série REF. Aos 180 dias, a substituição como a sílica de casca de arroz apresentou um desempenho superior de $14 \%$ ao ser comparada com a série REF. Os resultados obtidos confirmam a não existência de fissuras na matriz, uma vez que, se houvesse um quadro de fissuração avançado a resistência à tração seria visivelmente prejudicada. 

das Construções (40 SPPC), artigo 4SPPC126, pp. 243 - 252, 2019. DOI: 10.4322/2526-7248.046

De acordo com Irassar (1990) apud Souza, Medeiros e Hope Filho [5], no ensaio de resistência à tração na flexão, observa-se que a resistência aumenta com o tempo de exposição do ataque de sulfatos, até um ponto limite, a partir do qual se inicia um decréscimo da mesma, como uma parabólica, que marca o tempo de início da microfissuração das amostras.

Levando em consideração o trabalho apresentado pressupõem-se que os materiais estudados não atingiram o ponto de microfissuração necessário, devido ao ataque, para que a resistência à tração das amostras fosse prejudicada.

\subsection{MEV}

A Figura 4 apresenta as imagens de MEV obtidas para as três séries (REF, SCA e SA) nas condições estudadas, solução agressiva e referência (água saturada com hidróxido de cálcio). Nas Figuras 4, de A a C, nota-se a presença de produtos aciculares (indicados por setas) depositados nos poros, confirmados por EDS como etringita pelo percentual de enxofre disponível. Sendo assim, para as três séries foi possível identificar aspectos do ataque, com a formação de produtos deletérios. $O$ mesmo não ocorreu para as mesmas séries na condição referência, pois, em nenhuma delas, foi notada a presença de cristais aciculares nos poros, para a idade estudada.

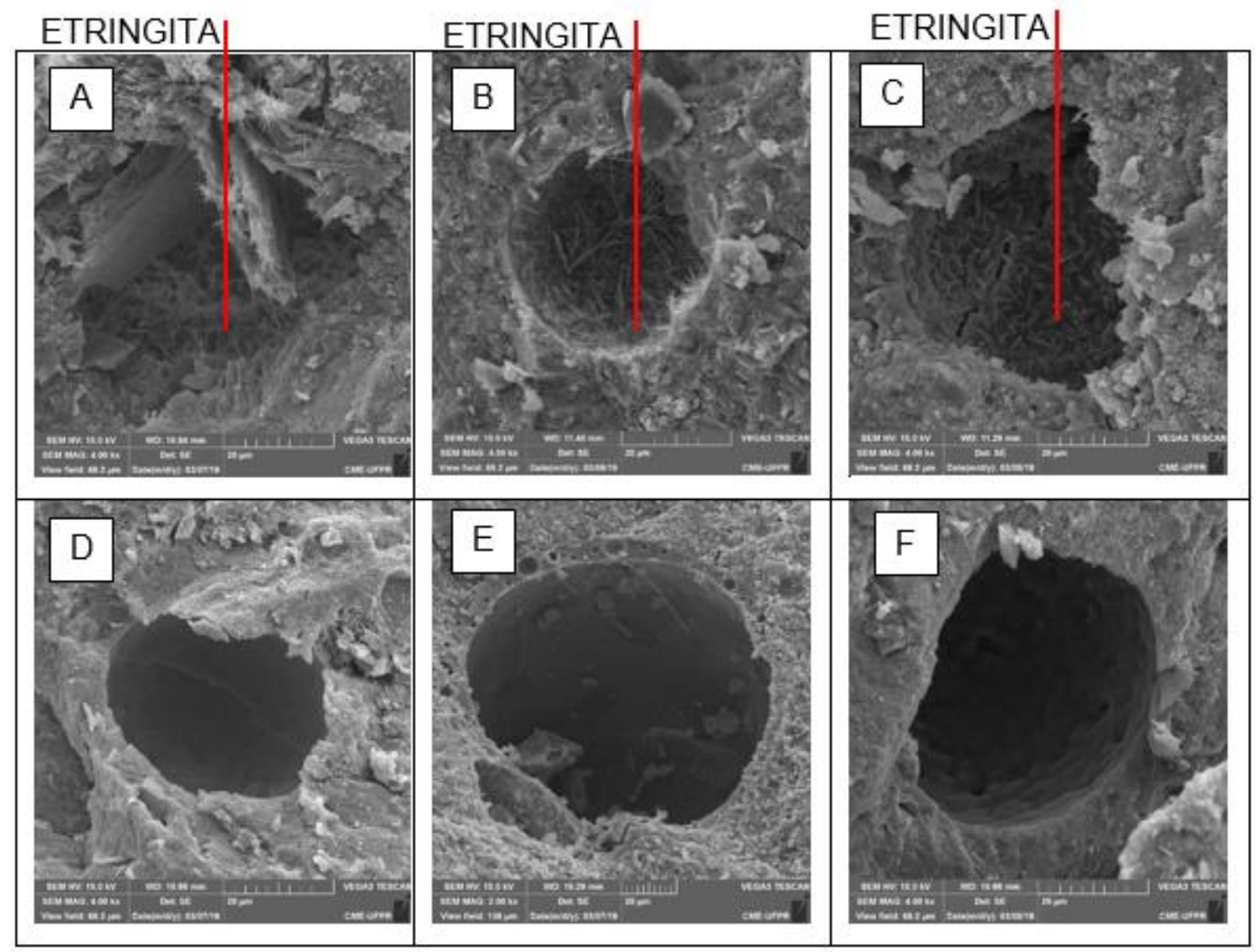

Figura 4: Imagens de MEV obtidas para as amostras sujeitas as condições de exposição. A, B e $C$ - solução agressiva de sulfato de magnésio, séries REF, SCA

e SA, respectivamente. D, E e F - solução referência, séries REF, SCA e SA, respectivamente. 
MEDEIROS, J.M.; ANDRADE, F. C.; CAPRARO, A. P.; MEDEIROS, M. H. F. CONCRETO COM SUBSTITUIÇÃO DE SÍLICA DE CASCA DE ARROZ E SÍLICA ATIVA: EFEITOS DO ATAQUE POR SULFATO DE MAGNÉSIO. $4^{\circ}$ Simpósio Paranaense de Patologia das Construções (40 SPPC), artigo 4SPPC126, pp. 243 - 252, 2019. DOI: 10.4322/2526-7248.046

As fotos dos ensaios de MEV indicar a presença de produtos deletérios para as séries expostas a solução agressiva e os outros ensaios ainda não apresentarem redução nas suas propriedades corrobora que o ataque ainda estaria em um estágio inicial, e que estudos semelhantes deveriam ser desenvolvidos por um período maior de tempo para avaliação do fenômeno.

\section{Conclusão}

Considerando os resultados obtidos pelas resistências à compressão e a resistência a tração dos concretos através dos gráficos, analisou-se os resultados da substituição da sílica da casca de arroz (SCA) com sílica ativa (SA), verificou-se resultados muito próximos com a série REF, não sendo possível afirmar com este experimento que tais substituições pozolânicas influenciaram na mitigação dos efeitos do ataque externo do sulfato de magnésio, entretanto, outros experimentos já realizados apontam os benefícios das pozolanas na melhora das resistências mecânicas do concreto.

Neste experimento verificou-se que as substituições das pozolânicas (cinzas de casca de arroz e sílica ativa) apresentaram pouca influência diretamente no ataque de sulfato de magnésio nas idades iniciais, pode-se inferir que a relação $\mathrm{C}_{3} \mathrm{~S} / \mathrm{C}_{2} \mathrm{~S}$ do clínquer possui pouca influência na solução de sulfato de magnésio.

Os resultados comprovam o ataque agressivo do sulfato de magnésio ao cimento Portaland dentro do período de 180 dias em solução agressiva com concentração de $7 \%$ de $\mathrm{MgSO}_{4}$, pelas imagens de MEV com análise de EDS, ficou comprovado que a degradação está em progresso, com a formação de etringita nos poros da matriz cimentícia das três séries estudadas na solução agressiva.

Deste modo, como recomendação futura, os autores sugerem a realização de novos estudos, com novos percentuais de adições e com maiores períodos de estudo.

\section{Agradecimentos}

Os autores agradecem a Fundação Araucária, a Universidade Federal do Paraná (UFPR), ao Departamento de Construção Civil (DCC), ao Programa de PósGraduação em Engenharia de Construção Civil (PPGECC), ao Centro de Estudos de Engenharia Civil (CESEC), ao Laboratório de Materiais e Estruturas (LAME) e ao grupo de pesquisa de Patologia e Recuperação das Construções (PRC).

\section{Referências}

[1] Ramezanianpour, A. M.; Hooton, R. D. Thaumasite sulfate attack in Portland and Portland-limestone cement mortars exposed to sulfate solution. Construction and Building Materials, Vol. 40, 2013.

[2] Dyer, T. Durabilidade do Concreto. Rio de Janeiro: Editora Moderna, 2015.

[3] Collepardi, A state-of-the-art review on delayed ettringite attack on concrete Cement and Concrete Composites. Volume 25, Issues 4-5, May-July 2003.

[4] Neville, A. M; Brooks, J. J. Tecnologia do concreto. Porto Alegre. Editora. Bookman. 2013. 

das Construções (40 SPPC), artigo 4SPPC126, pp. 243 - 252, 2019. DOI: 10.4322/2526-7248.046

[5] Souza, D. J. DE; Medeiros, M. H. F.; Hoppe Filho, J. Evaluation of the SR Portland cement against sodium and magnesium sulfate attack: a physical and comparative analysis of mortars. Revista IBRACON DE ESTRUTURAS E MATERIAIS, v. 11, p. 1053-1075, 2018.

[6] Mehta, P. K.; Monteiro, P. J. M. Concreto: microestrutura, propriedades e materiais. 3 ed. São Paulo: IBRACON, 2014.

[7] Dal Molin, D.C.C. Adições Minerais para Concreto Estrutural. In: Concreto: Ensino, Pesquisa e Realizações. São Paulo: IBRACON, 2005.

[8] Medeiros, M. H. F.; Raisdorfer, J. W.; Hoppe Filho, J. Influência da sílica ativa e do metacaulim na velocidade de carbonatação do concreto: relação com resistência, absorção e relação a/c. AMBIENTE CONSTRUÍDO (ONLINE), v. 17, p. 125-139, 2017.

[9] [Rahman, M. M; Bassuoni, M, T; Thaumasite sulfate attack on concrete: Mechanisms, influential factors and mitigation. Construction and Building Materials. 2014.

[10] Marchand, J, Skalny, P. Materials Science of Concrete: Sulfate Attack Mechanis Wiley-American Ceramic Society 1999. 